\title{
Stator winding fault diagnosis in permanent magnet synchronous generators based on short-circuited turns identification using extended Kalman filter
}

\author{
Brice Aubert $^{1,2,3}$, Jérémi Régnier ${ }^{1,2}$, Stéphane Caux ${ }^{1,2}$, Dominique Alejo ${ }^{3}$ \\ ${ }^{1}$ Université de Toulouse ; INPT, UPS ; LAPLACE ; ENSEEIHT, 2 rue Charles Camichel, BP 7122, F-31071 Toulouse cedex 7, France \\ ${ }^{2}$ CNRS ; LAPLACE ; F-31071 Toulouse, France \\ ${ }^{3}$ AEROCONSEIL - AKKA TECHNOLOGIES GROUP ; 3 rue Dieudonné Costes; F-31703 Blagnac, France
}

\section{ABSTRACT}

This paper deals with an Extended Kalman Filter based fault detection for inter-turn short-circuits in Permanent Magnet Synchronous Generators. Inter-turn short-circuits are among the most critical faults in the PMSG. Indeed, due to permanent magnets, the shortcircuit current is maintained as long as the machine is rotating. Thus, a specific PMSG faulty model in the $d$-q frame is developed to estimate the number of short-circuited turns which are used to build a fault indicator. Simulation results demonstrate the sensitivity and the robustness of the proposed fault indicator against various operation points on an electrical network even for a few number of short-circuited turns.

\section{Section: RESEARCH PAPER}

Keywords: Extended Kalman Filter; fault diagnosis; on-line parameters estimation; Permanent Magnet Synchronous Generator; inter-turn short-circuit

Citation: Brice Aubert, Jérémi Régnier, Stéphane Caux, Dominique Alejo, Stator winding fault diagnosis in permanent magnet synchronous generators based on short-circuited turns identification using extended Kalman filter, Acta IMEKO, vol. 3, no. 4, article 3, December 2014, identifier: IMEKO-ACTA-03 (2014)04-03

Editor: Paolo Carbone, University of Perugia

Received October $5^{\text {th }}, 2013$; In final form January $4^{\text {th }}, 2014$; Published December 2014

Copyright: () 2014 IMEKO. This is an open-access article distributed under the terms of the Creative Commons Attribution 3.0 License, which permits unrestricted use, distribution, and reproduction in any medium, provided the original author and source are credited

Funding: (none reported)

Corresponding author: Brice Aubert, e-mail: brice.aubert@laplace.univ-tlse.fr or brice.aubert@aeroconseil.com

\section{INTRODUCTION}

Permanent Magnet Synchronous Generators (PMSG) are increasingly used in various industrial fields such as aerospace, railway and automotive sectors or renewable energy [1] to take advantage of their high efficiency, small size and easy control for variable-speed applications compared to a wounded rotor design. With regard to safety considerations, the main drawback of PMSG is the critical effect of inter-turn short-circuits in stator windings. Indeed, stator faults in PMSG still remain while the machine is rotating because of the permanent rotor flux caused by magnets. More specifically, inter-turn short-circuits in stator windings are tricky to detect and are the root of highest fault currents, especially for a few number of faulty turns [2].

Thus, an early on-line detection is required to perform the appropriate safety request and to avoid greater damage. As well as being quick, the detection method should be robust to electrical network variations to avoid false alarms. Moreover, the constraints related to on-line monitoring considerations imply a detection algorithm matching the performances of on-board computers.

In the literature, three main approaches are commonly used to detect inter-turn short-circuits in stator windings. A first approach, based on signal analysis, often uses spectral tools to underline specific frequency components related to the fault. For example, stator current analysis in Park's [2], Concordia [3] or three-phase's [4] frame and axial flux leakage measurements [5] can be used as an inter-turn shortcircuit fault indicator. Even if these methods are compatible with on-line requirements and enable relatively quick fault detection, they are not suitable for variable-speed 
applications and are not robust with regard to electrical network variations in generator operation.

The second approach is related to knowledge-based methods which imply an a priori knowledge of fault signature to allow an a posteriori fault classification during the monitored system operation. Artificial intelligence tools as fuzzy logic system [6], artificial neural networks [7] and pattern recognition methods [8] can be used but time response and computation considerations are not matching with on-line detection requirements.

The third approach is based on state or parameters estimation and implies the use of mathematical models of the studied system [9]. These methods are a good compromise between robustness with regard to electrical network variations, on-board computation and fast fault detection. To meet these requirements, the chosen method presented in this paper for inter-turn short-circuit detection is based on the identification of the short-circuited turns ratio in a faulty PMSG model expressed in Park frame using an Extended Kalman Filter (EKF) algorithm. Traditionally used for state or parameter estimation, the EKF algorithm is, in this case, specifically adapted for detection purposes. A basic modelling approach allows defining a generalized algorithm suitable for a large power scale of synchronous generators. No additional measurements are required because the proposed detection scheme is fed with measurements already available for control purposes.

This paper is organized as follow: in section 2, the faulty PMSG Park model used for fault diagnosis is described. Section 3 presents simulation results of the EKF algorithms in both healthy and faulty conditions. The proposed fault indicator built is also described. Finally, a robustness and a sensitivity analysis are presented in section 4 to assess the proposed indicator effectiveness.

\section{FAULTY PMSG MODEL FOR INTER-TURN SHORT-CIRCUIT DETECTION}

The faulty PMSG model used for inter-turn short-circuit detection is based on an earlier study [10] with less modelling assumptions (voltage drops due to short-circuit reduction is taken into account) to make the PMSG model more sensitive to windings faults. The model enables the fault localization with the use of angle $\theta_{s / c}$ (equal to $0,2 \pi / 3$ or $4 \pi / 3$ for a short-circuit respectively on phase $A$, phase $B$ or phase $\mathrm{C}$ ) and the number of short-circuit turns $n_{s} / c$ (ratio

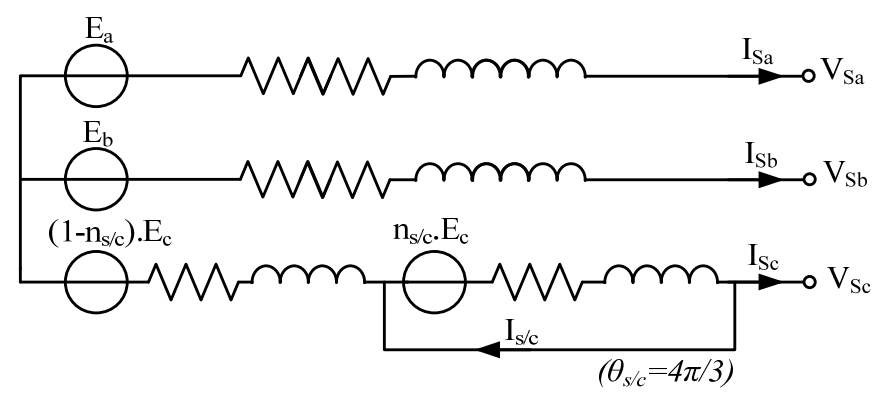

Figure 1. Faulty PMSG model used for inter-turn short-circuit diagnosis. between short-circuited turns and all turns on a stator winding). Figure 1 shows this model used for the fault diagnosis with inter-turn short-circuit located on phase $C$ $\left(\theta_{s / c}=4 \pi / 3\right)$.

According to this faulty model, the stator voltages $\left[V_{S}\right]$ and the short-circuit loop equations are respectively given in (1) and (2):

$$
\begin{aligned}
& {\left[V_{S}\right]=-R_{S} \cdot\left[I_{S}\right]-n_{s / c} \cdot R_{S} \cdot T_{s / c} \cdot I_{s / c} \cdot\left[\dot{\Phi}_{S}\right]} \\
& 0=n_{s / c} \cdot R_{S} \cdot T_{s / c}{ }^{T} \cdot\left[I_{S}\right]+n_{s / c} \cdot R_{S} \cdot I_{s / c}+\dot{\Phi}_{s / c}
\end{aligned}
$$

where the stator flux [Фs] and the short-circuit flux $\theta_{\mathrm{s} / \mathrm{c}}$ are respectively expressed in (3) and (4):

$$
\begin{aligned}
{\left[\dot{\Phi}_{\mathrm{S}}\right]=} & {[L] \cdot\left[\dot{I}_{S}\right]+\sqrt{\frac{3}{2}} \cdot n_{s / c} \cdot L_{p s} \cdot T_{32} \cdot\left[\begin{array}{l}
\cos \theta_{\mathrm{s} / \mathrm{c}} \\
\sin \theta_{\mathrm{s} / \mathrm{c}}
\end{array}\right] \cdot \dot{I}_{\mathrm{s} / \mathrm{c}}+} \\
& +n_{s / c} \cdot L_{l s} \cdot T_{s / c} \cdot \dot{I}_{\mathrm{s} / \mathrm{c}}-[E] \\
\dot{\Phi}_{\mathrm{s} / \mathrm{c}}= & \sqrt{\frac{3}{2}} \cdot \mathrm{n}_{\mathrm{s} / \mathrm{c}} \cdot \mathrm{L}_{\mathrm{ps}} \cdot\left(\mathrm{T}_{32} \cdot\left[\begin{array}{c}
\cos \theta_{\mathrm{s} / \mathrm{c}} \\
\sin \theta_{\mathrm{s} / \mathrm{c}}
\end{array}\right]\right) \cdot\left[\dot{\mathrm{I}}_{\mathrm{S}}\right]+ \\
+ & \mathrm{n}_{\mathrm{s} / \mathrm{c}} \cdot \mathrm{L}_{\mathrm{ls}} \cdot \mathrm{T}_{\mathrm{s} / \mathrm{c}}^{\mathrm{T}} \cdot\left[\dot{\mathrm{I}}_{\mathrm{S}}\right]+\mathrm{n}_{\mathrm{s} / \mathrm{c}}^{2} \cdot\left(\mathrm{L}_{\mathrm{ps}}+\mathrm{L}_{\mathrm{ls}}\right) \cdot \mathrm{I}_{\mathrm{s} / \mathrm{c}}-\mathrm{n}_{\mathrm{s} / \mathrm{c}} \cdot \mathrm{T}_{\mathrm{s} / \mathrm{c}}^{\mathrm{T}} \cdot[\mathrm{E}]
\end{aligned}
$$

with

$\left[V_{S}\right] \quad:$ Stator voltages vector

$\left[I_{s}\right] \quad:$ Stator currents vector

$I_{s / c} \quad:$ Short-circuit current

$[E] \quad$ : Electromotive forces vector

$R_{S} \quad:$ Stator resistance of a stator winding

Lls $\quad$ : Leakage inductance of a stator winding

$L_{p s} \quad$ : Magnetizing inductance of a stator winding

$[L]=\left[\begin{array}{ccc}L_{l s}+L_{p s} & -L_{p s} / 2 & -L_{p s} / 2 \\ -L_{p s} / 2 & L_{l s}+L_{p s} & -L_{p s} / 2 \\ -L_{p s} / 2 & -L_{p s} / 2 & L_{l s}+L_{p s}\end{array}\right]:$ Inductance matrix

$\left[T_{32}\right]=\frac{1}{\sqrt{3}} \cdot\left[\begin{array}{cc}\sqrt{2} & 0 \\ -1 / \sqrt{2} & \sqrt{3 / 2} \\ -1 / \sqrt{2} & -\sqrt{3 / 2}\end{array}\right]:$ Concordia transformation

matrix

$\mathrm{T}_{\mathrm{s} / \mathrm{c}}=\frac{1}{3} \cdot\left[\begin{array}{c}1+2 \cdot \cos \left(\theta_{\mathrm{s} / \mathrm{c}}\right) \\ 1+2 \cdot \cos \left(\theta_{\mathrm{s} / \mathrm{c}}-\frac{2 \pi}{3}\right) \\ 1+2 \cdot \cos \left(\theta_{\mathrm{s} / \mathrm{c}}-\frac{4 \pi}{3}\right)\end{array}\right]:$ Short-circuit matrix

After Park transformation applied to (1) and (2) and some calculations, the faulty model can be expressed with these two equations (5) and (6):

$$
\begin{aligned}
{\left[\mathrm{V}_{\mathrm{S}}\right]_{\mathrm{dq}}=} & -\mathrm{R}_{\mathrm{S}} \cdot\left[\mathrm{I}_{\mathrm{S}}^{\prime}\right]_{\mathrm{dq}} \omega \cdot \mathrm{L}_{\mathrm{S}} \cdot\left[\begin{array}{cc}
0 & -1 \\
1 & 0
\end{array}\right] \cdot\left[\mathrm{I}_{\mathrm{S}}^{\prime}\right]_{\mathrm{dq}}-\mathrm{L}_{\mathrm{S}} \cdot\left[\mathrm{I}_{\mathrm{S}}\right]_{\mathrm{dq}}+ \\
& +[\mathrm{E}]_{\mathrm{dq}} \\
{\left[I_{S}\right]_{d q}=} & {\left[I^{\prime} S\right]_{d q}-\left[\tilde{I}_{s / c}\right]_{d q}=\left[I_{S}^{\prime}\right]_{d q}-\frac{1}{\left[Z_{s / c}\right]_{d q}} \cdot\left[V_{S}\right]_{d q} }
\end{aligned}
$$

where:

Stator synchronous inductance: $L_{S}=3 / 2 \cdot L_{p s}+L_{l s}$ Park transformation matrix: $P(\theta)=\left[\begin{array}{cc}\cos \theta & -\sin \theta \\ \sin \theta & \cos \theta\end{array}\right]$ 
Short-circuit fault impedance:

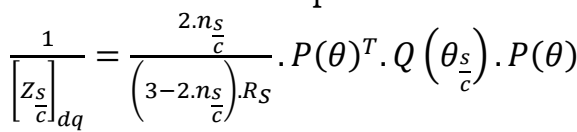

Fault localization matrix:

$Q\left(\theta_{\frac{s}{c}}\right)=\left[\begin{array}{cc}\cos ^{2}\left(\theta_{\frac{s}{c}}\right) & \cos \left(\theta_{\frac{s}{c}}\right) \cdot \sin \left(\theta_{\frac{s}{c}}\right) \\ \cos \left(\theta_{\frac{s}{c}}\right) \cdot \sin \left(\theta_{\frac{s}{c}}\right) & \sin ^{2}\left(\theta_{\frac{s}{c}}\right)\end{array}\right]$

Short-circuit current calculation in Park frame:

$\left[\tilde{I}_{\bar{s}}\right]_{d q}=P(\theta)^{T} \cdot \sqrt{\frac{2}{3}} \cdot n_{\bar{s} \cdot} \cdot\left[\begin{array}{c}\cos \left(\theta_{\frac{s}{c}}\right) \\ \sin \left(\theta_{\frac{s}{c}}\right)\end{array}\right] \cdot I_{\frac{s}{c}}$

It can be noticed that (5) is the same equation as a classic healthy PMSG model taking into account [IS'] as the stator current whereas the inter-turn short-circuit loop is represented in (6) with the equivalent fault impedance $\left[Z_{s} / c\right]$ at the output of the machine which deflects a part of the stator current.

Expending this model to each phase, three short-circuit impedances $\left(Z_{s / c A}, Z_{s / c B}, Z_{s / c C}\right.$ for $\theta_{s / c}=0,2 \pi / 3,4 \pi / 3$ respectively) are added to the PMSG model as shown in Figure 2.

This model can be written as a state space representation with [IS'] as the state vector. The inter-turn fault is expressed in the feedforward matrix $D$, depending on the number of short-circuited turns $n_{s} / c A, n_{s} / c B, n_{s} / c C$.

To estimate these parameters in this non-linear model, the EKF algorithm is used. In the EKF algorithm, special attention should be paid to covariance matrices tuning, particularly for the measurement noise covariance matrix $R$ and the state noise covariance matrix $Q$ to obtain, at the same time, an accurate estimation and an appropriate dynamic response of the extended parameters [11]. In order to satisfy the fast dynamic response requirement for the fault indicator and according to noise measurements, the covariance matrices used for the estimation of each $n_{s} / c$ are expressed in (7):

$P_{0}=10^{-1} \cdot I_{5 \times 5} ; R=10^{-2} \cdot I_{2 \times 2} ; Q=10^{-5} \cdot\left[\begin{array}{cc}I_{2 \times 2} & 0 \\ 0 & 10^{-4} \cdot I_{3 \times 3}\end{array}\right]$

Simulations results are presented in the following section.

\begin{tabular}{|c|c|c|c|}
\hline \multicolumn{3}{|c|}{ PMSG Characteristics } & Stator windings \\
\hline Rated Power & 3,6 & $\mathrm{~kW}$ & $\mathrm{~A}^{\cdot}$ \\
\hline Rated Voltage & 73 & $\mathrm{~V}$ & \\
\hline Rated Current & 15,1 & A & \\
\hline Rated Speed & 2000 & $\mathrm{rpm}$ & \\
\hline Resistance at $20^{\circ} \mathrm{C}-\mathrm{Ph}$ to $\mathrm{Ph}$ & 0,59 & $\Omega$ & \\
\hline Inductance - $\mathrm{Ph}$ to $\mathrm{Ph}$ & 7 & $\mathrm{mH}$ & \\
\hline Number of poles & 4 & poles & \\
\hline Number of turns per phase & 72 & turns & \\
\hline
\end{tabular}

Figure 2. PMSG characteristics and its stator windings.

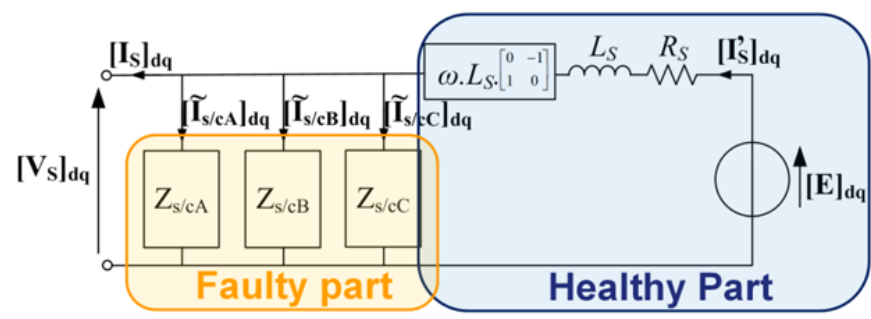

Figure 3. Inter-turn faulty PMSG model expressed in Park's frame.

\section{SIMULATION PROCEDURE}

\subsection{Simulation Test Bench Setup}

The PMSG studied in this paper is an existing threephase $3.6 \mathrm{~kW}$ four-pole Permanent Magnet Synchronous Machine (Figure 3). Stator windings of PMSG are modified with additional connection points in the stator coils on Phase A, allowing the introduction of several inter-turn short-circuit levels using a short-circuit resistance $R_{S C}(4 \%$, $8 \%, 12 \%$ and $16 \%$ of short-circuit turns respectively corresponding to 3, 6, 9 and 12 turns on 72 whole turns of a stator winding).

The faulty PMSG model used for simulation is built using the Electrically Coupled Magnetic Circuit (ECMC) method [12]. It consists in a semi-analytical computation of the PMSG inductances from the stator winding layout including additional connections for inter-turn short-circuit generation.

The simulation test bench is set with SABER software in order to generate various operating points for the faulty PMSG model (Figure 4). It is composed of a balanced R-L load to vary the electrical power and the power factor, an unbalanced $\mathrm{R}$ load to create power unbalanced and a harmonic load including a three-phase diode bridge rectifier with resistive load to generate current harmonics.

\subsection{Simulation Results}

As shown in Figure 5, where a $16 \%$ inter-turn shortcircuit is generated at $t=0.5 \mathrm{~s}$ on phase $\mathrm{A}$, each estimated parameter $n_{s / c}$ is impacted.

Indeed, a modification of their mean value and large oscillations at twice the electrical frequency appear as soon as the winding fault occurs (Figure $5 \mathrm{~b}$ ). It is also noticeable that $n_{s / c A}$ is not the only estimated parameter sensitive to the short-circuit: $n_{s / c B}$ and $n_{s / c C}$ are also modified in a lesser extent due to some simplifying assumption about the faulty PMSG model used for the parameters estimation. However, the fault can clearly be located on phase A in this test.

According to this test, the proposed fault indicator to

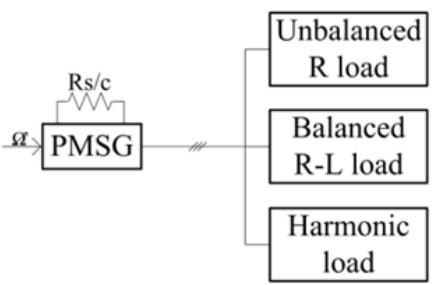

Figure 4. Simulation test bench scheme. 

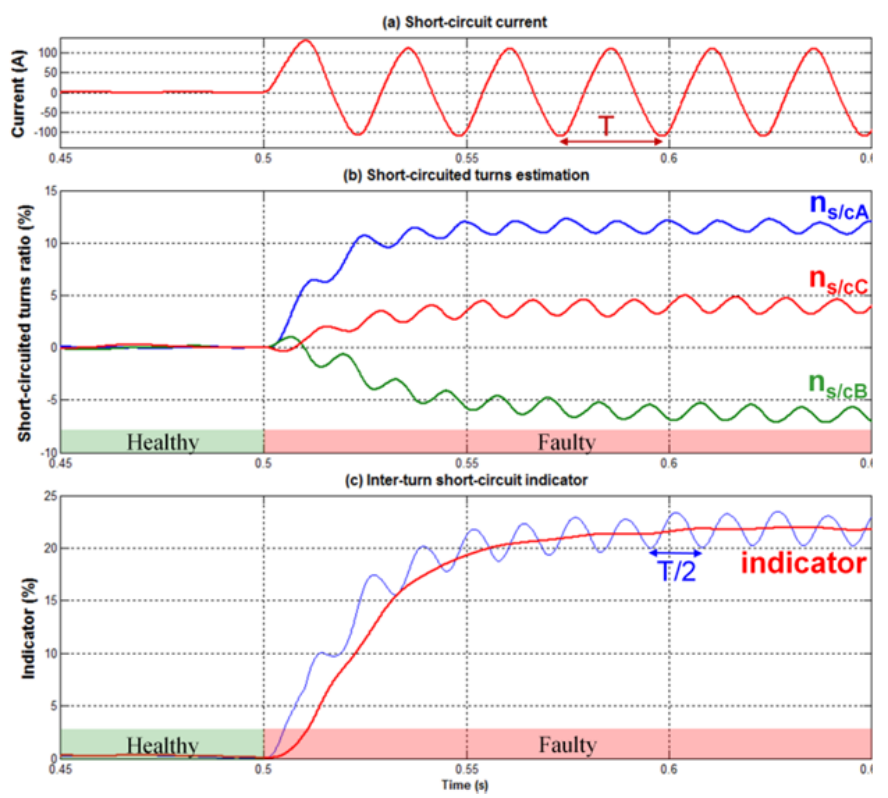

Figure 5. Response to a $16 \%$ inter-turn short-circuit ( $\mathrm{I}_{\text {LOAD }}=10 \mathrm{~A}$ per phase, $40 \mathrm{~Hz}$ ). (a) Short-circuit current. (b) Estimated parameters. (c) Fault indicator.

detect inter-turn short-circuits expressed in (8) is based on the sum of these three estimated short-circuited turn ratios (Figure 5c). A moving average calculation over one electrical half period is added to filter the fault indicator and improve its robustness.

Fault_indicator $=\sum_{i=A, B, C}\left(\mid n_{\mathrm{s} / \mathrm{c}} /_{i}\right)_{T / 2}$

Figure 6 shows the evolution of this fault indicator in the healthy case (for $t<0.5 \mathrm{~s}$ ) and in the faulty case (for $t$ $>0.5 \mathrm{~s}$ ) with several values of short-circuited turns on phase A. In the healthy case, the fault indicator remains close to 0 , reflecting a safe PMSG. In faulty cases, the fault indicator increases with the number of short-circuited turns, which confirms that the fault detection is trickiest for a few number of short-circuited turns. However, shortcircuit detection remains possible even for $4 \%$ of shortcircuited turns in comparison with the fault indicator

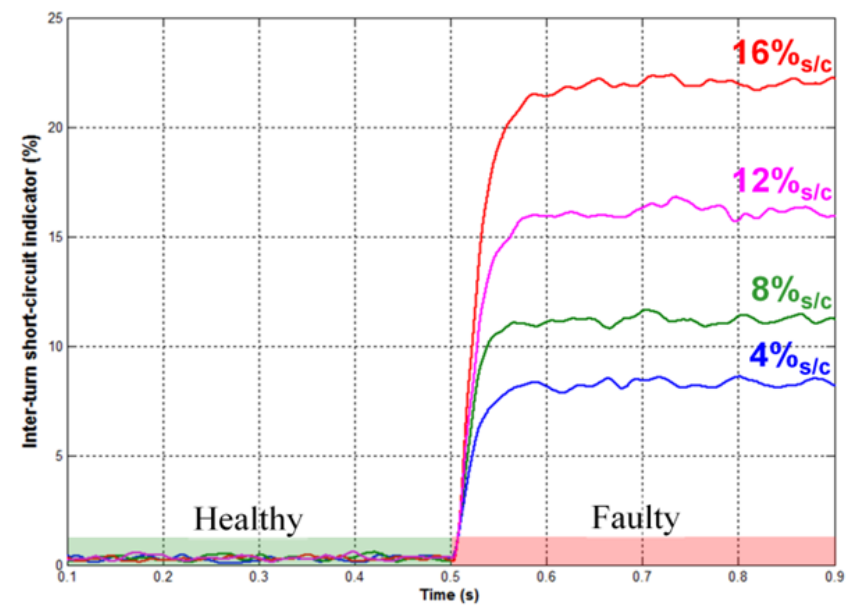

Figure 6. Fault indicator response to various inter-turn short-circuits ( $\mathrm{I}_{\mathrm{LOAD}}=$ 10 A per phase, $40 \mathrm{~Hz}$ ). behavior in the healthy case. Moreover, time response of the proposed fault indicator remains quick (about $20 \mathrm{~ms}$ ) in spite of the filtering characteristic of the moving average calculation.

In the following section, the effectiveness of this fault indicator is evaluated against several operating points and several inter-turn short-circuit.

\section{FAULT INDICATOR PERFORMANCE ASSESSMENT}

\subsection{Robustness Assessment}

In order to evaluate the robustness of each estimated parameter to the inter-turn short-circuit diagnosis, several tests based on Figure 4 have been made and are listed below:

Test 1 - Frequency variation from $30 \mathrm{~Hz}$ to $60 \mathrm{~Hz}$ with $10 \mathrm{~Hz}$ step and $10 \mathrm{~A}$ load current per phase.

Test 2 - Power variation from 15 A to 0 A load current per phase with $2.5 \mathrm{~A}$ step and $40 \mathrm{~Hz}$ electrical frequency.

Test 3 - Power factor variation from 1 to 0.8 with 0.05 step at $40 \mathrm{~Hz}$ and $10 \mathrm{~A}$ load current per phase.

Test 4 - Unbalanced load variation from $-5 \mathrm{~A}$ to $+5 \mathrm{~A}$ unbalanced load current with $2.5 \mathrm{~A}$ step at $40 \mathrm{~Hz}$ and $10 \mathrm{~A}$ load current in other phases.

Test 5 - Harmonic load variation from $0 \%$ to $20 \%$ of nominal current harmonic distortion variation with 5\% step at $40 \mathrm{~Hz}$ and $10 \mathrm{~A}$ load current phases per phase.

These scenarios are related to specifications that could be encountered in embedded electrical networks. The robustness is then characterized by the ability of the EKF algorithm to properly separate the healthy and the faulty cases whatever the operating conditions. To quantify this ability, healthy and faulty simulations are performed under the same operating conditions and the worst indicator's value is kept for each test (i.e. the highest indicator's value in the healthy case and the lowest indicator's value in the faulty case). For example, Figure 7 shows the evolution of the fault indicator for various operating electrical frequencies. In this test, the highest fault indicator values in healthy cases appear at the lowest frequency whereas the lowest fault indicator values in faulty cases appear at the

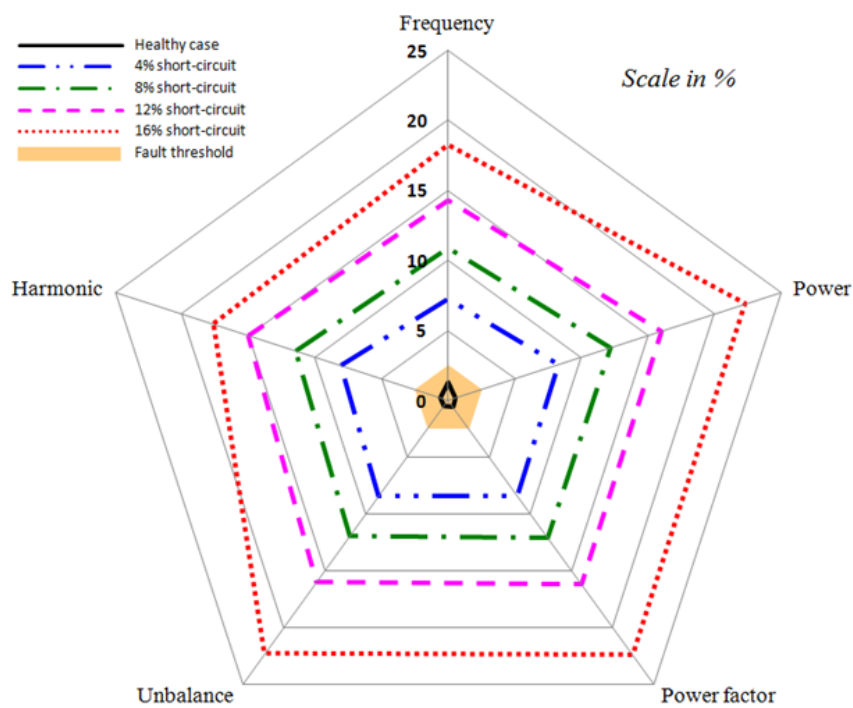

Figure 7. Robustness spider chart for the proposed fault indicator. 


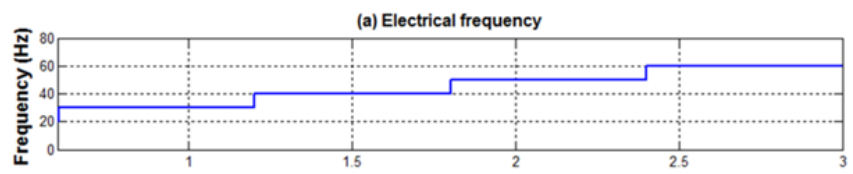

(b) Short-circuit current for $16 \%$ inter-turn short-circuited
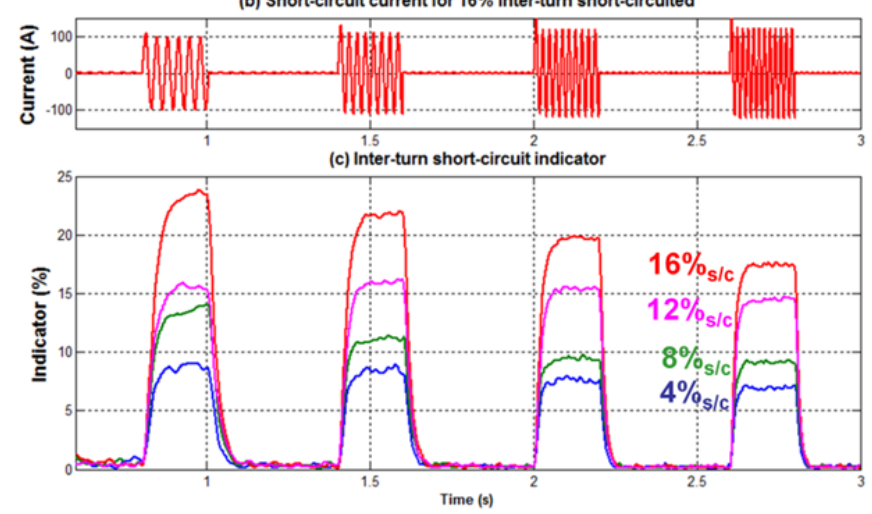

Figure 8. Fault indicator response to various electrical frequencies (I LOAD $=10$ A per phase). (a) Electrical frequency. (b) Short-circuit current. (c) Fault indicator.

highest frequency.

The following spider chart (Figure 8) summarizes the robustness of the proposed fault indicator against electrical network variation, using the worst indicator's values for each test, to compare healthy and faulty operation with several short-circuited turns. It indicates that an inter-turn short-circuit fault can be easily distinguished from the healthy PMSG whatever the operating conditions and even for a few number of short-circuited turns.

According to these robustness tests, a detection threshold is set at twice the maximum of the fault indicator in healthy condition for each robustness test, in order to avoid any false alarms in healthy operation. This maximum fault indicator value in healthy case appears at the lowest frequency in the frequency tests. Thus, the detection threshold is set to $2.5 \%$ and is also represented in Figure 8.

\subsection{Sensitivity Assessment}

The sensitivity assessment consists in the evaluation of the short-circuit current needed to detect the inter-turn fault. It can be calculated according to the detection threshold previously determined. Figure 9 shows this sensitivity test in which the short-circuit resistance $R s C$ is used to vary the inter-turn short-circuit severity.

This test confirms that the fault detection is trickier and more serious for a few number of short-circuited turns. Indeed, in relation to the $15 \mathrm{~A}$ rated current of the studied PMSG, a fault current of $45 \mathrm{~A}$ is required to detect a $4 \%$ inter-turn short-circuit compared to a $15 \mathrm{~A}$ fault current required to detect a $16 \%$ inter-turn short-circuit. However, stator windings of a PMSG can easily withstand three times the rated current during the detection time (about $20 \mathrm{~ms}$ ). Moreover, these results show that, even for a few number of short-circuited turns, an early detection of a resistive interturn short-circuit is possible with the proposed fault indicator.

\section{CONCLUSIONS}

This paper describes a method for inter-turn short-

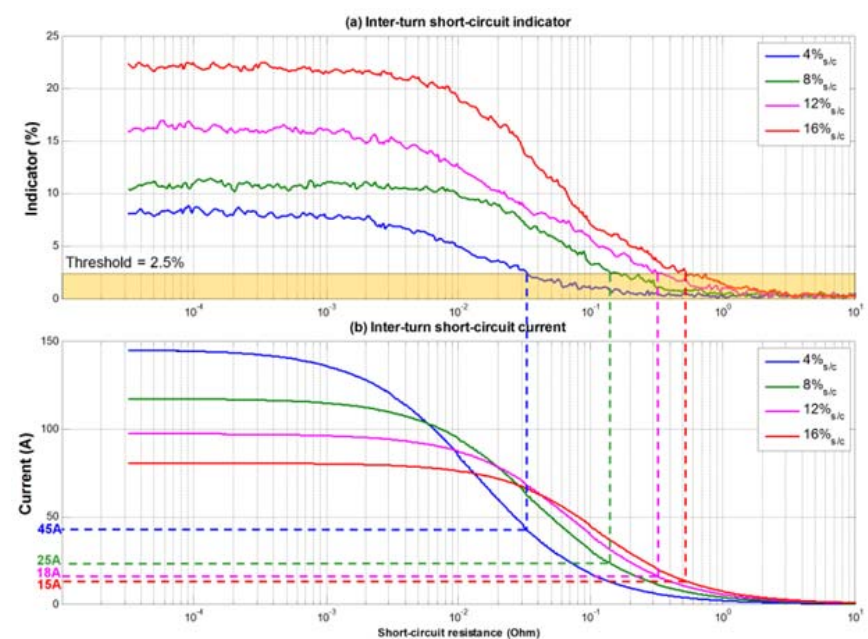

Figure 9. Sensitiveness assessment for the proposed fault indicator ( LOAD $_{\text {LO }}=$ 10 A per phase, $40 \mathrm{~Hz}$ ). (a) Fault indicator. (b) Short-circuit current.

circuit detection in stator windings based on a short-circuit turns estimation on a faulty PMSG model using an EKF algorithm. This fault diagnosis allows a fast and robust detection of inter-turn short-circuit, whatever the operating conditions on a non ideal electrical network even for a few number of short-circuited turns. Moreover, this fault indicator allows to localize the faulty phase and is also sensitive to resistive inter-turn short-circuit which could prevent a dead short-circuit.

Moreover, experimental tests have also been done with the short-circuit current limited to 25 Arms for safety considerations. Experimental results, available in [13], are quite similar to simulation ones and confirm the good representativeness of the simulation model even for a resistive inter-turn short-circuit.

Finally, the prospect of this study is the application of this fault indicator on a $45 \mathrm{~kW}, 400 \mathrm{~Hz}-800 \mathrm{~Hz}$ PMSG.

\section{REFERENCES}

[1] K.R. Weeber, M.R. Shah, K. Sivasubramaniam, A. El-Refaie, $\mathrm{Qu}$ Ronghai, C. Stephens, S. Galioto, "Advanced permanent magnet machines for a wide range of industrial applications", IEEE Power and Energy Society General Meeting, July 2529, 2010, Minneapolis, USA, pp. 1-6.

[2] S.M.A. Cruz, A.J.M. Cardoso, Multiple reference frames theory: A new method for the diagnosis of stator faults in three-phase induction motors, IEEE Trans. Energy Convers. 20 (2005) pp. 611-619.

[3] D. Diallo, M.E.H. Benbouzid, D. Hamad, X. Pierre, Fault detection and diagnosis in an induction machine drive: $\mathrm{A}$ pattern recognition approach based on Concordia stator mean current vector, IEEE Trans. Energy Convers. 20 (2005) pp. $512-519$.

[4] M. Sahraoui, A. Ghoggal, S.E. Zouzou, A. Aboubou, H. Razik, "Modelling and detection of inter-turn short circuits in stator windings of induction motor", Proc. Int. IECON, 2006, pp. 4981-4986.

[5] J. Penman, H.G. Sedding, B.A. Lloyd, W.T. Fink, Detection and Location of Interturn Short Circuits in the Stator Windings of Operating Motors, IEEE Trans. Energy Convers. 9 (1994) pp. 652-658. 
[6] M.A. Awadallah, M.M. Morcos, S. Gopalakrishnan, T.W. Nehl, A neuro-fuzzy approach to automatic diagnosis and location of stator inter-turn faults in CSI-fed PM brushless DC motors, IEEE Trans. Energy Convers. 20 (2005) pp. 253 259.

[7] M.B.K. Bouzid, G. Champenois, N.M. Bellaaj, L. Signac, K. Jelassi, An effective neural approach for the automatic location of stator interturn faults in induction motor, IEEE Trans. Ind. Electron. 55 (2008) pp. 4277-4289.

[8] A. Soualhi, G. Clerc, H. Razik, "Faults classification of induction machine using an improved ant clustering technique”, IEEE International Symposium on Diagnostics for Electric Machines, Power Electronics \& Drives (SDEMPED), Sept. 5-8, 2011, Bologna, Italy, pp. 316-321.

[9] M. Khov, J. Regnier, J. Faucher, "Detection of turn shortcircuit faults in stator of PMSM by on-line parameter estimation", International Symposium on Power Electronics,
Electrical Drives, Automation and Motion (SPEEDAM), June 11-13, 2008, Ischia, Italy, pp. 161-166.

[10] S. Bachir, S. Tnani, J.-C. Trigeassou and G. Champenois, Diagnosis by parameter estimation of stator and rotor faults occurring in induction machines, IEEE Trans. Ind. Electron. 53 (2006) pp. 963 -973.

[11] B. de Fornel, J.-P. Louis, "Electrical Actuators: Identification and Observation", ISTE Ltd, 2010.

[12] A.A. Abdallah, J. Regnier, J. Faucher, "Simulation of Internal Faults in Permanent magnet Synchronous Machines", $6^{\text {th }}$ International Conference on Power Electronics and Drive Systems, Nov. 28 - Dec. 1, 2005, Kuala Lumpur, Malaysia, pp. 1390-1395.

[13] B. Aubert, J. Regnier, S. Caux, D. Alejo, "On-line inter-turn short-circuit detection in permanent magnet synchronous generators", IEEE International Symposium on Diagnostics for Electric Machines, Power Electronics \& Drives (SDEMPED), Aug. 27-30, 2013, Valencia, Spain, pp. 329-335. 